\title{
Global experience of HVDC composite insulators in outdoor and indoor environment
}

https://doi.org/10.1515/rams-2020-0050

Received Sep 20, 2019; accepted Aug 06, 2020

\begin{abstract}
High-voltage direct current (HVDC) transmission is known as green-energy transfer technology and has recently become an attractive alternative of high-voltage alternating current (HVAC) due to its high-power transmission capability and lower power loss. Use of composite insulators on direct current (DC) transmission lines experienced rapid growth in recent years due to their high hydrophobicity and better performance in contaminated environment than conventional ceramic insulators. During their service operation on DC lines, insulators are prone to more accumulation of contaminants due to unidirectional electric field. The contaminants under wet conditions allow leakage current to flow on the insulator surface. Being organic in nature, polymeric insulators have a tendency to age under the combined effects of electrical and environmental stresses. To fully understand the longterm aging performance of DC composite insulators, a detailed survey was considered necessary. Towards that end, this paper critically summarizes worldwide experience of aging performance of composite insulators in the field as well as in laboratory conditions.
\end{abstract}

Keywords: Insulation, fillers, silicone rubber, RTV-coating, Inclined plane testing

\section{Introduction}

Nowadays, HVDC technology is an energy-efficient and economical solution for transmission and distribution of bulk power over a large distance. HVDC offers several advantages over HVAC such as reduced cost, high power transmission capability, less corona losses, im-

\footnotetext{
${ }^{\star}$ Corresponding Author: Basharat Mehmood: Faculty of Electrical Engineering, GIK Institute of Engineering Sciences and Technology, Topi, 23640, Pakistan; Email: basharat.uet2012@gmail.com Mohammad Akbar: Faculty of Electrical Engineering, GIK Institute of Engineering Sciences and Technology, Topi, 23640, Pakistan
}

proved power system stability, smaller tower sizes, etc. [14]. Outdoor insulators play a vital role in the efficient and reliable transmission of electrical power. Globally, composite insulators are progressively replacing the conventional ceramic insulators due to their lightweight, high hydrophobicity, better contamination performance, lower cost, excellent vandalism resistance, and high dielectric and mechanical strength [5-8].

Composite insulators, being organic in nature are prone to aging during their service life. The polymer materials exhibit flexible and weaker ionic bonds due to which they have a tendency to degrade in external environments $[9,10]$. Degradation of these materials is caused by the breakdown of polymer macromolecules causinga reduction in molecular weight due to electrical and environmental stresses. As a result, withstand capability of voltage reduces which can lead to flashover [11, 12]. The surface properties of these materials are deteriorated by long-term exposure to these stresses, which adversely affect their service performance and also reduce the life expectancy of these insulators [13].

Among all types of polymeric insulators, silicone rubber (SiR) insulators have shown superior hydrophobic properties and consequently demonstrated better pollution flashover performance [14, 15]. To further improve its characteristics, different fillers such as alumina trihydrate (ATH), silica $\left(\mathrm{SiO}_{2}\right)$ etc. have been added. The ATH filler $\left(\mathrm{Al}_{2} \mathrm{O}_{3} \cdot 3 \mathrm{H}_{2} \mathrm{O}\right)$ enhances the resistance to tracking as well as erosion while silica imparts mechanical strength to the SiR [16]. Both the HVDC technology and SiR insulators present many advantages for reliable operation of a power system. However, studies have shown that different challenges have to be coped with on DC lines due to these polymeric insulators. Compared with AC insulators, DC insulators exhibited higher failure rates due to which they require advancement in their design $[17,18]$. Also, the accumulation of pollution is more in case of $\mathrm{DC}$ which reduces the flashover voltage of DC insulators [19]. It is, therefore, necessary to conduct research and investigate the performance of DC composite insulators.

The reliability and long-term performance of composite insulators under DC stress need to be investigated in outdoor environmental conditions as they undergo aging

¿ Open Access. (c) 2020 M. Akbar and B. Mehmood, published by De Gruyter. 
due to different types of stresses (Ultraviolet (UV) radiations, heat, contamination etc). The performance of these insulators in service is strongly affected by the contamination accumulated on the surface as well as due to material aging. To better understand that several researchers have investigated the aging performance of SiR insulators in natural environment as well as artificially through laboratory simulations.

This paper presents a worldwide survey of the field as well as the laboratory aging performance of the HVDC composite insulators and room-temperature vulcanized silicone rubber (RTV-SiR) coated insulators.

\section{Field experience of HVDC composite insulators}

Various types of insulators have been used on HVDC transmission and distribution systems globally and a variety of aging studies have been performed. Sorquist and coworkers compared the long-term field aging performance of silicone rubber, ethylene propylene diene monomer (EPDM) and porcelain insulators which were energized at +300 kV DC for seven years at a field station of Anneberg, located in a coastal region of Sweden [20]. The area has marine type pollution having organic and salty ingredients coming from seaside get deposited on the insulators due to heavy winds. This results in the development of dry band arcing due to the flow of leakage current and eventually the loss of hydrophobicity. The hydrophobicity is a surface property which is evaluated by Swedish Transmission Research Institute (STRI) hydrophobicity method [21] The degree of water repellency of a polymer surface is divided into seven hydrophobicity classes (HCs) with HC1 representing a completely hydrophobic surface and HC7 referring to a completely hydrophilic surface. The study found that non-uniform pollution deposition and material deterioration are key factors affecting the in-service performance of polymeric insulators. The analysis of leakage current data, hydrophobicity measurement and material characterization through various diagnostic techniques (ESCA and FTIR) indicated that the aging performance of silicone rubber insulators filled with ATH is better than porcelain and EPDM insulators. The EPDM insulators allowed heavy current arcs (25-100 mA) and resulted in greater loss of hydrophobicity ( $\mathrm{HC} 5-\mathrm{HC} 7)$ while SiR insulators displayed low discharge activities $(<25 \mathrm{~mA})$ and maintained their hydrophobicity (HC2-HC-3). A good correlation was obtained between the surface conditions and leakage current data. Moreover, EPDM insulators filled with silicone low molecu- lar weight (LMW) constituents reported low values of leakage current and good hydrophobicity.

Ahmadi-Joneidi et al. [22] investigated the aging performance of 3 to 9 years' field-exposed $20 \mathrm{kV}$ hightemperature vulcanized HTV-SiR/ATH insulators installed on overhead distribution lines in a coastal, highly humid and heavily polluted areas of Iran. The insulators remained exposed to harsh environmental conditions i.e. high humidity $(80 \%)$, high UV radiations and salt deposition. Measurements of equivalent salt deposit density (ESDD), non-soluble deposit density (NSDD) and electrical conductivity were made as per IEC 60507 [23] to assess the site pollution severity based on classification given in [24] which are shown in Table 1 [22]. A lifetime of 18-24 year was predicted after condition assessment of these insulators using various physical (visual inspection), electrical (salt fog test, STRI hydrophobicity test), mechanical (Thermogravimetric analysis (TGA), Tensile test etc.) and material diagnostic tests using Fourier transform infrared spectroscopy (FTIR) and energy dispersive X-ray analysis (EDX). In the salt fog test, the authors considered the following criteria as the end of lifetime of field-aged insulators i.e. when there are visual signs of tracking, weather sheds are punctured and erosion of $\mathrm{SiR}$ housing reaches the core of insulators with erosion depth of $3 \mathrm{~mm}$. In addition, the reduction of elongation-at-break to $50 \%$ in tensile test was also used as criteria for end of lifetime. SiR insulators with 3 to 4 years of service exposure showed no notable surface defects while 7 to 9 years, field-aged insulators exhibited the presence of surface cracks, contamination layer on the surface, slight discoloration of sheds, erosion of material surface and oxidation on high-voltage (HV) side of end-fittings. All the insulators also showed loss in hydrophobicity (STRI class HC3-HC4) and an increase in leakage current after exposure to the natural environment. Decrease in percent elongation while an increase in hardness and brittleness of insulating materials were observed with exposure to the environmental conditions. The insulators also showed loss of weight as well as loss of $\mathrm{CH} 3$ group. It was suggested that utilities should continuously monitor these insulators for any degradation. SiR insulators performed well in heavily polluted environments as compared to ceramics and other polymeric insulators.

Lee et al. [25] reported Queensland Electricity Commission's 16 years of field experience with ceramics and composite insulators (SiR and EPDM) installed on $110 \mathrm{kV}, 132$ $\mathrm{kV}$, and $275 \mathrm{kV}$ lines in clean and polluted environments of Australia. Ceramic insulators showed higher values of ESDD than composite insulators, which required washing of ceramic insulators after a period of 18 months. No notable defects and flashover activities were observed on 
Table 1: ESDD, NSDD and conductivity measurements on five, $20 \mathrm{kV}$ SiR insulators.

\begin{tabular}{ccccccc}
\hline Type & $\begin{array}{c}\text { Operation time } \\
(\text { year })\end{array}$ & $\begin{array}{c}\text { Leakage } \\
\text { distance }(\mathrm{mm})\end{array}$ & $\begin{array}{c}\text { ESDD } \\
\left(\mathrm{mg} / \mathrm{cm}^{2}\right)\end{array}$ & $\begin{array}{c}\text { NSDD } \\
\left(\mathrm{mg} / \mathrm{cm}^{2}\right)\end{array}$ & $\begin{array}{c}\text { Conductivity } \\
(\mu \mathrm{S} / \mathrm{cm})\end{array}$ & $\begin{array}{c}\text { Pollution severity as per IEC } \\
60815\end{array}$ \\
\hline $\mathrm{A}$ & 3 & 720 & 0.164 & 0.52 & 648.15 & Heavy-Very Heavy \\
$\mathrm{B}$ & 4 & 880 & 0.273 & 0.135 & 685.65 & Heavy-Very Heavy \\
$\mathrm{C}$ & 7 & 890 & 0.261 & 0.784 & 643.54 & Very Heavy \\
$\mathrm{D}$ & 8 & 960 & 0.358 & 0.509 & 1260 & Very Heavy \\
$\mathrm{E}$ & 9 & 860 & 0.418 & 0.746 & 1501.12 & Very Heavy \\
\hline
\end{tabular}

EPDM insulators installed in light and moderate polluted areas. For heavily polluted areas, however, EPDM insulators showed several problems such as erosion of the material, discoloration, cracking, radial splits of sheds near HV end, axial splits on polymer sheath, external and internal flashovers. Based on this study, the EPDM insulators were recommended for use in light and moderate polluted areas. The marine pollution deposited on insulators became conductive upon wetting which resulted in the development of surface leakage current. It was found that the leakage current is affected primarily by relative humidity and rain. All insulators became wetted and showed hydrophilic surface during the period of heavy rain. It was however, reported that lower leakage current was measured on SiR insulators as compared with EPDM and ceramic insulators. In addition, $\mathrm{SiR}$ insulators maintained their hydrophobic nature intact during their operation which was attributed to continuous migration of silicone oil to the surface.

Mavrikakis et al. [26] analysed the condition of 10 years' filed-aged HTV-SiR insulator, installed on a $150 \mathrm{kV}$ transmission line in the coastal environment of Crete Island, Greece. The insulator remained exposed to a heavily polluted environment. The aging assessment was made using different diagnostic techniques involving visual inspection, STRI hydrophobicity classification, scanning electron microscopy (SEM), EDX, and FTIR. Using these techniques, the effects of aging, flashover and environmental contamination on field performance of SiR insulators were evaluated. Increased surface roughness and pollution accumulation were seen on the insulator. Flashovers were observed due to arcing which caused loss of hydrophobicity, depolymerization, changes in material surface morphology and damage to the arcing horns. The hydrophobicity of the flashed area of the surface was found higher than un-flashed area which was attributed to removal of pollution layer by arcing, which subsequently increased the LMV contents on the surface. Furthermore, it was found that the backbone group Si-O-Si got greatly affected by arcing and the material's surface was damaged up to a depth of $50 \mu \mathrm{m}$.
The authors [27] installed cylindrical silicone rubber insulators at a field station located inthe coastal environment of Sweden which were aged under both AC and DC stresses for a period of 32 months. SiR insulators filled with different amount of ATH filler and additional silicone oil were energized at $11.4 \mathrm{kV}_{p-g} \mathrm{AC}$ and $10 \mathrm{kV}$ DC with electrical stress levels of $50 \mathrm{~V} / \mathrm{mm}$ and $100 \mathrm{~V} / \mathrm{mm}$, respectively to accelerate the aging process. The creepage distances of these insulators wereonly $30 \%$ and $60 \%$ of what was used for ceramic insulators. Visual inspection and leakage current measurements were continuously made at the field site. Material characterization tests using SEM, X-ray photoelectron spectroscopy (XPS) and IR spectroscopy were conducted after 18 months of exposure to assess the degree of aging. During the period of severe salt-storm, rainy and windy conditions, the samples under DC stresses exhibited higher values of leakage current and more surface degradation than those under AC stress. A significant reduction of hydrophobicity (up to HC6) of samples was also seen during this period. After this period is over, all samples showed hydrophobicity recovery within 14 days and maintained at $\mathrm{HC} 1$ or $\mathrm{HC} 2$ until the next period of severe environmental conditions. It was reported that the creepage distance of DC energized samples had the largest effect on their electrical performance. The addition of silicone oil resulted in more pollution accumulation on the surface. However, the electrical activity and leakage current were suppressed due to the diffusion of the oligomer. The samples with lower ATH contents showed faster deterioration due to surface discharges than those loaded with higher ATH contents. The samples filled with a higher amount of filler contents showed a declined rate of degradation. Surface erosion was also observed and IR spectroscopy showed a major loss of ATH at eroded areas. The increase in surface temperature $\left(>450^{\circ} \mathrm{C}\right)$ was observed due to discharge activities which resulted in depolymerization. Moreover, XPS studies also showed a small degree of corona-induced surface oxidation [28] which however, did not contribute to major degradation. 
The comparison of long-term aging studies of polymeric insulators under both AC and DC stresses in a natural environment may provide a guideline for the optimum design of HVDC insulators. In that context, Vlastos et al. [29] studied the changes in electrical properties of $\mathrm{AC}$ and DC stressed EPDM insulators due to aging as well as the influence of material composition and insulator design on aging under severe environmental conditions. The EPDM insulators were energized at $+600 \mathrm{kV}$ DC and 800 $\mathrm{kV}$ RMSAC system voltage, respectively in polluted environment of Sweden. At the beginning of their energization, EPDM insulators performed better and remained hydrophobic with lower values of leakage current. With aging, they started experiencing flashovers which were more in case of DC than AC. The degradation of shed materials started earlier on insulators energized under DC stress showing the accelerating effect on aging. After a few years of application of environmental stresses (electrical, UV, pollution), surface cracking, hydrophobicity loss, erosion, and chalking were also observed on all types of insulators which were more severe for DC than AC. The study concluded that aging caused by $\mathrm{DC}$ voltage is more severe than AC.

HVDC SiR insulators are exposed to surface and corona discharges under DC stress due to which static charge accumulates on the surface of insulators which distorts the electric field as well as potential distribution that may cause flashover [30]. The charge dynamics is affected by three activities; namely conduction on the surface along the solid-gas interface, conduction in the bulk of the material and neutralization of surface charges by surrounding ionic carriers [31, 32]. Yuan et al. [33] studied and analyzed the surface potential decay (SPD) characteristics of virgin and in-service aged HTV-SiR insulator sheds filled with silica and aluminium hydroxide operated at $\pm 500 \mathrm{kV}$ and $\pm 800 \mathrm{kV}$ DC transmission lines in China. The samples from these lines were removed after 10 years and 6 years in service, respectively. During experiments, DC corona charges were deposited on the surface of the samples and surface potential decay was experimentally studied using the non-contact technique. In this technique, the sample is placed on a grounded plate and dc corona charges are induced on the sample by a needle electrode which is kept $5 \mathrm{~mm}$ above the sample. The potential caused by deposited charges on the surface was measured using a Kelvin probe connected to an electrostatic voltmeter kept $2 \mathrm{~mm}$ from the surface of the sample. The results of in-service aged SiR insulators were compared with the results of virgin specimens and the effect of material aging on surface potential profile and their decay were studied and the degree of material degradation was found. The role of bulk and surface conductivities was confirmed using a simulated model. It was reported that in the early period of decay, surface conduction was found dominant which was later surpassed by bulk conduction. Moreover, the authors concluded that decay measurements on fieldaged polymeric insulator weather sheds could be used for evaluating the degree of material aging.

In heavily polluted environment, the probability of insulator flashover increases. The increase in creepage distance of insulators and application of grease were not proper solutions to overcome flashover problems. Therefore, to overcome these problems, RTV coated insulator technology was adopted. Nowadays, ceramic insulators pre-coated with RTV are widely used on overhead HVDC lines to improve contamination flashover performance of ceramic insulators [34, 35]. This improvement is due to the transfer of hydrophobicity from the surface to the pollution layer. The hydrophobic nature of RTV coating is due to diffusion of LMW polydimethylsiloxane chains that move from the bulk of the coating to the surface. Also, the reorientation of the polydimethylsiloxane (PDMS) surface due to the rotation of hydrophobic methyl groups around the siloxane bond makes them hydrophobic [36, 37]. Generally, two types of RTV coated insulators are used on transmission line towers i.e. Pre-coated or factory-coated insulators and field coated insulators. In case of pre-coated insulators, the coating is applied in the industries while in case of field coated insulators, the coating is applied in the field once the insulators are assembled.

In 2009, TERNA, an Italian transmission system operator (TSO) introduced and installed RTV field-coated insulators for the first time on several towers of SACOI \pm 200 $\mathrm{kV}$ HVDC line located in coastal and industrial areas to reduce the summer pollution outages. At first, $1836 \mathrm{insu}$ lator units were installed which were later removed for laboratory tests. Marzinotto and co-workers [38] described TERNA's field experience with RTV-coated glass insulators. The results showed better performance of RTV coated glass insulators than their uncoated counterparts and no need for annual maintenance was required for the coated insulators. A useful lifetime of more than 10years was predicted for the coated insulators. Although no electrical activity was observed, but some cracks were seen on the coated insulators. Furthermore, the authors suggested a uniform coating thickness $(0.3-0.5 \mathrm{~mm})$ to be effective against moisture and pollution. Too thick coating can obstruct the selfshattering of glass insulators and detection of failed units cannot be easily determined. Too thin coating can get easily damaged during handling and shipment of insulators. The authors claimed that the half part of insulator coated with RTV-SiR is economically more feasible than a fully 
Table 2: DC pollution measurements on RTV-coated insulators.

\begin{tabular}{cccccc}
\hline Insulator & ESDD $\left(\mathrm{mg} / \mathrm{cm}^{2}\right)$ & NSDD $\left(\mathrm{mg} / \mathrm{cm}^{2}\right)$ & $\begin{array}{c}\text { IEC 60815 } \\
\text { Pollution Level }\end{array}$ & NSDD/ESDD & $\begin{array}{c}\text { Bottom/top } \\
\text { ESDD ratio }\end{array}$ \\
\hline \#1 top surface & 0.02 & 0.08 & Medium & 4 & 9 \\
\#1 bottom surface & 0.18 & 0.61 & Very heavy & 3.39 & \\
\#12 top surface & 0.02 & 0.05 & Medium & 2.5 & 9 \\
\#12 bottom surface & 0.18 & 0.66 & Very heavy & 3.67 & 9 \\
\hline
\end{tabular}

coated insulator as the latter is subject to damage during their transportation and handling.

Nowadays, RTV coated insulators are used on DC systems operating at voltage levels of 10 to $500 \mathrm{kV}$. The HVDC toughened glass insulators pre-coated with RTVSiR showed excellent pollution, electrical and mechanical performance effectively combining the properties of both glass and composite insulators [39]. RTV-SiR coating contains PDMS fluid and an adhesion promoter to enhance bonding to the surface of insulators [40]. Various fillers were added to the base matrix (PDMS) of RTV coating to improve its long-term performance. ATH was used to improve thermal conductivity and tracking and erosion resistance of the material by transferring heat from dry band arcing [41]. Fumed silica was added for increasing tensile strength of the coating and controlling its uniform flow. The coating is dissolved in a naphtha solvent which can easily transfer RTV to the surface. Electrical and physical properties of these coatings are largely dependent upon their composition [42].

Marzinotto et al. [43] also described the performance of pre-coated RTV toughened glass insulators removed after two years of installation from $\pm 200 \mathrm{kV}$ DC line in Tuscany and Sardinia, Italy. The insulators were exposed to highly industrial and marine pollution. Unified specific creepage distance of $49 \mathrm{~mm} / \mathrm{kV}$ was adopted for the DC line considering the type and severity of pollution at the site. Out of 18 insulator units, measurements were made on insulator unit \#1 and unit \#12 from the high voltage side. Some laboratory tests such as visual inspection, STRI hydrophobicity evaluation, pollution level, and pollution layer conductivity measurements were performed on these units. No major signs of electrical activity were found but some scrapes of small dimensions were seen indicating mechanical degradation caused due to handling operation. Accumulation of dirt was found on the bottom surface of insulator \#1. The top surface of insulators showed "medium" pollution level due to better cleaning caused aerodynamically or through washing of the surface by rain whereas bottom surface showed "very heavy" pollution level based on [44] as shown in Table 2 [43]. The value of conductivity of pollution layer was measured showing a very low value i.e. $0.13 \mu \mathrm{S}$. Furthermore, the top surface also retained better hydrophobicity compared with the bottom surface.

Biological contamination affects the performance of in-service composite and RTV-coated insulators. These contaminants include microbial bacteria, filamentous fungi, and single-celled algae growth which mainly cause deterioration, invasion, discoloration, and corrosion of these insulators [45]. Mostly, their growth occurs in highly humid and high temperature regions [46-49]. Different authors [50-52] reported a decrease in wet flashover voltage due to algae growth. Biological fouling due to algae growth reduces the performance of outdoor insulation. Ouyang et al. [53] acquired RTV-coated insulator samples from 500 $\mathrm{kV}$ DC transmission line in China after seven years of operation and the effect of algae growth on insulators was investigated. Hydrophobicity and partial surface conductivity tests were performed to measure the partial surface conductivity and hydrophobicity of algae and non-algae sections of the samples. It was reported that the hydrophobicity of algae parts was lower than non-algae parts of samples. This is due to the hydrophilic nature of algae. Moreover, partial surface conductivity of algae parts was found to be higher than non-algae parts indicating presence of more salt on the algae parts of samples.

\section{Indoor studies on HVDC insulators}

\subsection{Multi-stress aging studies}

Degradation of housing materials affects the long-term performance of composite insulators. Thus, aging studies were conducted globally by various researchers. Some of the existing laboratory tests used for accelerated aging with more reproducible and repeatable results were performed by different researchers [54-60]. These tests are useful for selection and ranking of composite insulators. 
The aging properties of polymeric insulators under DC stress have not been fully understood due to the absence of enough literature. Very few laboratory multi-stress aging studies were conducted on HVDC insulators. The DC multi-stress aging of polymeric insulators has notyet been standardized. IEC 62730 [61] and IEC62217 [62] were previously used providing testing procedures for multi stress aging of AC-energized polymer insulators [63]. The design of testing procedures for multi stress aging under DC stress is still a challenging task and is under consideration.

Several authors investigated aging of polymeric materials under humidity and UV stresses and found that SiR performed better than others [64-67]. Increase in hardness and depolymerization were found in polymeric insulators after exposure to UV radiations and heat [68-70]. The effect of accelerated aging was reported in the form of increase in leakage current, loss of hydrophobicity, surface cracking, salt deposition and depolymerization [71-74].

Verma et al. [75] studied the effect of combined stresses on the aging performance of DC energized HTV SiR/ATH filled insulators under controlled climatic conditions for an aging period of 1000 hours. The authors performed indoor aging tests in prevailing environment of India. Multiple stresses like temperature, humidity, UV and DC stress were applied in a timely/cyclic manner in a climatic chamber. Diagnostic techniques like SEM along with EDX were employed to monitor surface micro-structural changes of the aged samples and to identify the elemental composition on the surface, respectively. The FTIR was also used for identifying molecular level changes and degree of depolymerization in the material. The study also conducted hydrophobicity class measurements using the spray method according to IEC/TS 62073 [76] in which sample was inclined at an angle of $10^{\circ}-35^{\circ}$ from the horizontal. The water was sprayed and images were captured which were then compared with standard images to measure the hydrophobicity class. The TGA was conducted to find the loss of ATH contents with increasing temperature. SEM micrographs showed surface cracks and roughness while EDX measurements indicated changes in the elemental composition of the surface. The FTIR results indicated depolymerization and loss of main hydrocarbon $\left(\mathrm{CH}_{3}\right)$ groups which led to degradation of material properties. TGA analysis presented the loss of ATH components which further accelerated the process of thermal degradation. The loss of hydrophobicity was observed and HC6 class was measured on the aged sample which increases surface discharges. It has been reported that this study is quite useful to understand the multi stress aging behavior of polymeric insulators under DC stress.
The $5000 \mathrm{~h}$ multi-stress aging test method presented by IEC does not properly simulate the influence of nonsoluble contamination and process of hydrophobicity change on the long-term performance of SiR insulators. Moreover, these test methods are not appropriate for $\mathrm{SiR}$ insulators used in inland areas having a high degree of contamination. Liang et al. [77] proposed a novel and modified $5000 \mathrm{~h}$ test method i.e. THU for multi stress aging of polymeric insulators. In this method, two main modifications were made. First, the salt fog was replaced by contamination fog containing both soluble $(\mathrm{NaCl})$ and nonsoluble (kieselguhr) pollutants. The Second, enough time was provided for SiR to transfer and recover its hydrophobicity. A total of eight insulators having different shed designs and material composition were tested at $-23.4 \mathrm{kV}$ DC in a newly designed test setup containing a fog chamber and a UV chamber in a laboratory environment of China. The chosen values of ESDD and NSDD were very close to those measured in the actual field of inland areas. Discharge activities along with loss of hydrophobicity in discharge areas were seen on SiR insulators. Some specimens also showed severe tracking and erosion with the same damaging pattern as found in the field. The authors claimed that this modified $5000 \mathrm{~h}$ method could be useful for proper ranking of SiR insulators and simulation of the hydrophobicity-change process and contamination conditions. It was also suggested that a comparison of long-term performance and ranking of insulators can be made using both IEC and THU $5000 \mathrm{~h}$ test procedures.

\subsection{Inclined plane tracking and erosion aging tests on composite insulators}

The surface of polymeric insulators is exposed to contamination during operation in service and after certain time, contamination layer starts building up on the surface. In the presence of water droplets and contamination layer, loss of hydrophobicity occurs which results in the formation of a conductive film on the surface $[78,79]$. The electrical discharges and dry band arcing occur on the insulator surface which produce a large amount of heat in the discharge area which causes the tracking and erosion on the surface of insulator and insulator may lose its dielectric property completely [80-86].

Tracking is a carbonaceous and dielectric breakdown phenomenon on the insulator surface caused by discharges in the presence of contamination. Erosion is an irreversible process which causes degradation and weight loss of insulator housing material. The surface discharges vary with electric field and chances of tracking increases 
with increase in wetting and contamination severity [87, 88]. The surface degradation due to tracking is more severe under DC stress as it attracts more pollution accumulation on HVDC insulators than HVAC [89-91]. The development of tracking on the surface of an insulating material in contaminated environment is also affected by the composition of materials [92]. The polymeric insulators used on HVDC lines are so designed to have increased creepage distance for improving the tracking and erosion performance. However, the tracking and erosion resistance of SiR insulators can also be enhanced by adding the micron and nanosized additives like silica $\left(\mathrm{SiO}_{2}\right)$, ATH $\left(\mathrm{Al}_{2} \mathrm{O}_{3} \cdot 3 \mathrm{H}_{2} \mathrm{O}\right)$ etc. [93-98]. Usually, ATH and alumina fillers are added to improve the tracking and erosion performance of SiR insulators. The ATH filler provides better thermal conductivity to SiR composites than silica [18]. Moreover, ATH has the ability to release water of hydration when the local temperature at the dry band arcing (DBA) area exceeds $220^{\circ} \mathrm{C}$, thus removing heat from the DBA area. However, this release can also cause roughness of the surface which can further lead to wetting and DBA [99]. Silica, a semi-reinforcing filler, improves the physical and dielectric properties of $\mathrm{SiR}$ composites due to molecular bonding with the SiR polymer base matrix [100]. It has also been found that nano fillers improved the erosion resistance and dielectric performance of nano composites [101-103].

The dry band arcing on SiR insulators erodes the housing and thereby exposes fibre glass core to moisture. Inorganic fillers such as ATH and silica are added to the $\mathrm{SiR}$ to enhance its tracking and erosion resistance and the hydrated fillers help in physical cleaning of surface residue thus decreasing the surface temperature and enhancing the erosion resistance $[104,105]$. The enhanced thermal conductivity by the addition of ATH or silica also reduces the erosion of SiR composites [106]. The intense, stable dry band arcing and longer discharge periods that severely erode the SiR insulators have been reported under DC stress [107, 108].

The inclined plane tests (IPT) were performed on different polymer insulating materials to ascertain their aging. It measures the tracking and erosion resistance and degree of aging in a polymers insulating material. The ASTM D2303 [109] and IEC 60587 [110] are used globally to provide test methods for inclined plane testing of composite insulators. The test is useful in providing a procedure for assessing the suitability of insulating materials in the presence of surface discharges. The test is more severe than actual service conditions and results in the surface aging of materials in an accelerated way with a high level of reproducibility which is beneficial for comparison of different materials.
In IPT, a sample is mounted on a flat surface making an angle of $45^{\circ}$ with the horizontal. A pair of electrodes made from stainless steel are attached to both ends of the sample surface. The upper electrode is attached to either positive or negative pole of DC power supply through a current limiting resistor while the other electrode is connected to ground. Filter papers are usually employed on the high voltage electrode to introduce liquid contaminant and to ensure the development of a steady filament between the two electrodes. The data acquisition system is used to record leakage current using a sampling resistor. After fixing the sample between the test electrodes, the $\mathrm{NH}_{4} \mathrm{Cl}$ solution having a conductivity of $2.5 \mathrm{mS} / \mathrm{cm}$ is supplied with a flow rate of $0.3 \mathrm{ml} / \mathrm{min}[111,112]$. After $15 \mathrm{~min}$, DC voltage is applied to develop discharge activities on the surface of the sample. Concurrently, the temperature distribution developed on the surface is recorded using an infrared thermal imager.

In USA, Moreno and Gorur et al. [113] conducted an experimental study on AC and DC corona and electrical performance of polymer insulators in indoor Arizona environment. Silica filled epoxy, ATH filled SiR and ethylene vinyl acetate (EVA) were employed. Surface charge accumulation and their decay trends were investigated which were used to evaluate performance of these insulators. In this study, more surface charge accumulation and longer duration discharges were observed on DC energized insulators showing the worst electrical performance of DC insulators than AC energized insulators. The loss of hydrophobicity was reported upon exposure to pollution and DC stress. When compared to $\mathrm{AC}$, the resistance to tracking and erosion was also found lower in the case of DC stressed insulators.

In India, Chandrasekar and co-workers [114] analyzed the surface degradation of SiR insulators due to tracking under different profiles of voltage $(4.5 \mathrm{kV}$ AC and $+4 \mathrm{kV}$ $\mathrm{DC})$. The leakage current on the surface of thermally-aged samples was higher both under AC and DC voltages compared to the virgin samples. It was found that thermal and mechanical properties were also affected due to thermal degradation of insulating materials. Materials having higher values of activation energy, showed greater tracking time and vice versa. Bruce et al. [115] evaluated degradation mechanism of SiR samples under both polarities of DC in a laboratory located in Manchester, UK. The results showed that under positive DC voltage, higher values of erosion depth, peak current, and mass loss were recorded. It was also reported that material degradation and tracking can vary with test conditions.

Vas et al. [116] performed the DC IPT as per ASTM D2303 on different SiR samples filled with micro ATH (30 
wt.\%) and nano alumina (4 wt.\%) under both positive and negative DC voltages and concluded that tracking as well as erosion performance of nano-composites is better than the micro-filled composites for both polarities even at lower percentage loading as the number of nano particles of a filler is more than micro-sized particles thus providing higher resistance against tracking and erosion. Du et al. [111] studied the effect of different loading schemes of boron nitride (BN) nano particles on the tracking and erosion resistance of RTV-SiR and a correlation was obtained between thermal conductivity and tracking and erosion resistance. The experimentation was conducted in a laboratory environment of China. The results showed that increasing filler content from 0 to $7 \mathrm{wt} . \%$, the thermal dissipation and conductivity got improved. The weight loss, erosion depth, discharges, and dry band arcing also decreased which improved the tracking and erosion resistance of SIR/BN composites.

Ghunem and co-workers [117] compared the results of DC IPT test of HTV-SiR and EPDM insulating materials both filled with $25 \mathrm{wt} . \%$ ATH under both positive and negative polarities in an indoor laboratory of Ontario, Canada. An earlier failure was reported under negative DC voltage for both types of insulators showing lower resistance to tracking and formation of dry band arcing. Irregular dry band arcing and flaming failure were found in EPDM elastomers whereas stable discharges (intensified by ionization activity) were observed on SiR elastomers. The authors [118] studied the DBA erosion suppression mechanism of ATH and silica filled HTV and liquid silicone rubber composites in DC IPT and reported that thermal conductivity of the composites got improved by the addition of ATH and silica fillers and thereby contributed in minimizing surface temperature. The increased amount of ATH or silica reduced the DBA temperature. The study further reported that 30 wt.\% of ATH filler impedes the development of hot spots on the surface. The heat capacity of ATH filled composites got enhanced due to the water of hydration of ATH which does not allow an increase in surface temperature locally. The improvement in the withstand capability of stable and intense DBA of SiR composites makes them suitable for DC outdoor insulation applications.

In HVDC power transmission, epoxy has been widely used as an insulating sleeve in power converter transformer and flywheel material in wind power applications [119]. Nano fillers are added to the epoxy base matrix to enhance its properties. Alapati et al. [120] reported that the addition of aluminium oxide $\left(\mathrm{Al}_{2} \mathrm{O}_{3}\right)$ in low-density polyethylene (LDPE) reduces partial discharge. It has also been reported that nano $\mathrm{Al}_{2} \mathrm{O}_{3}$ filler particles greatly improve the dielectric properties of epoxy composites [121].
The authors [122] investigated the tracking behavior of epoxy resin nano composites under both AC and DC voltages with different percentages (1 to $10 \mathrm{wt} . \%$ ) of organic nano clay. The tracking tests were performed in indoor environment of Chennai, India. Different physicochemical analysis techniques were employed after the tracking test including wide-angle X-ray diffraction (XRD), TGA and transmission electron microscopy (TEM). It was reported that tracking is more severe under negative DC. Moreover, high leakage current and less tracking time were reported under negative polarity. With the increase of nano content, the leakage current decreased and the tracking time also increased. The surface hydrophobicity also decreased with tracking. The addition of $5 \mathrm{wt} . \%$ of nano clay filler in epoxy resulted in intercalated structure and the maximum aging/degradation of epoxy occurred at $300^{\circ} \mathrm{C}$.

Du et al. [123] performed IPT under positive polarity on epoxy $/ \mathrm{Al}_{2} \mathrm{O}_{3}$ nano composites following the modified IEC 60112 in a laboratory in China. The effect of 1,3,5 and $7 \mathrm{wt} \%$ of $\mathrm{Al}_{2} \mathrm{O}_{3}$ nano particles as filler in the epoxy base matrix on tracking and erosion resistance was studied. Increase in tracking time, decrease both in weight loss and discharge intensity were observed by increasing nano- $\mathrm{Al}_{2} \mathrm{O}_{3}$ content from 0 to $5 \mathrm{wt} \%$. The opposite tendency was observed by increasing filler content from 5 to $7 \mathrm{wt} \%$ in epoxy nano composites. Zhaoliang Xing et al. [124] studied the tracking behavior of epoxy/nano-magnesium oxide ( $\mathrm{MgO})$ composites with filler content of $0.1,1,2,6$, and $10 \mathrm{wt} . \%$ and reported that both tracking resistance as well as contact angle got improved with the increase of nano additives. The same tendency was observed in tracking resistance and hydrophobicity measurements resulting in fewer surface discharges. Moreover, reduced surface resistivity was observed which is useful for releasing surface charges and thereby hindering the distortions in the electric field.

\section{Conclusion}

In this paper, an attempt has been made to review the long-term aging performance of DC composite insulators exposed to various stresses in the field as well as in laboratory multi-stressed conditions. In addition, a survey of the use of RTV-coated insulators on DC lines is also presented. Following is the main outcome of this detailed review:

- A long-term exposure of DC composite insulators to various outdoor environmental and electrical stresses cause aging of these insulators which influence their in-service performance and reduce their service life. 
- The degradation due to electrical and environmental stresses is judged through loss of hydrophobicity, increase in leakage current, loss of fillers, depolymerization, surface cracking, chalking, discoloration, reduction in mechanical properties, tracking and erosion of shed materials.

- The degradation of polymeric insulators depends on the type of electric stress, outdoor environmental stresses (pollution, humidity, UV, heat, salt, fog, rain), types of housing materials and fillers, design and construction of a composite insulators.

- The degradation under DC stress is accelerated and more severe under negative polarity.

- As compared to AC energized composite insulators, DC energized composite insulators displayed higher loss of electrical, physical, thermal and mechanical properties.

- The key contributing aging factor has been recognized as the loss of hydrophobicity which makes the surface of insulators wettable.

- SEM, EDX, FTIR, XRD, XPS and TGA are key diagnostic tools to evaluate the severity of aging.

- The long-term aging performance of composite insulators improves by the addition of anti-aging additives such as alumina, trihydrate, silica, boron nitride, clay particles and magnesium oxide etc.

- Among various types of fillers, ATH and silica particles are considered as more appropriate anti-aging fillers due to their high thermal stability, high mechanical strength and high tracking and erosion resistance.

- Nano composites showed better performance than micro composites under multi-stressed indoor laboratory studies.

- Among all types of composite insulators, SiR insulators showed better performance in heavily polluted environments due to their excellent contamination flashover performance, high hydrophobicity and excellent tracking and erosion resistance.

- EPDM insulators showed excellent performance at the beginning of their service life in light and moderate polluted conditions. In heavily polluted environment, EPDM insulators showed higher values of leakage current and higher reduction of hydrophobicity than SiR insulators.

- RTV-coated glass insulators showed improved performance during their service life on DC transmission lines. A uniform-coating thickness (0.3-0.5mm) has been recommended for improved performance of coated insulators.
- A well-coordinated research program including indoor and outdoor studies at global level may be a way forward to get ready for future where power transmission through DC lines could be the most attractive proposition for global transfer of electrical energy in the most efficient way.

\section{References}

[1] Larruskain, D. M., I. Zamora, O. Abarrategui, and Z. Aginako. Conversion of $A C$ distribution lines into $D C$ lines to upgrade transmission capacity. Electric Power Systems Research, Vol. 81, No. 7, 2011, pp. 1341-1348.

[2] Smede, H., C. G. Johansson, O. Winroth, and H.P. Schutt. Design of HVDC converter stations with respect to audible noise requirements. IEEE Transactions on Power Delivery, Vol. 10, No. 2, 1995 , pp. 747-758.

[3] Yu, J., G. G. Karady, and L. Gu. Applications of embedded HVDC in power system transmission. In IEEE Power Engineering and Automation Conference, September 18-20, 2012, Wuhan, China, pp. 1-6.

[4] Nilsson, D., and A. Sannino. Efficiency analysis of low-and medium-voltage DC distribution systems. In IEEE Power Engineering Society General Meeting, June 6-10, 2004, Denver, Colorado, USA, pp. 2315-2321.

[5] Kikuchi, T., S. Nishimura, M. Nagao, K. Izumi, Y. Kubota, and M. Sakata. Survey on the use of non-ceramic composite insulators. IEEE Transactions on Dielectrics and Electrical Insulation, Vol. 6, No. 5, 1999, pp. 548-556.

[6] Schneider, H. M., J. F. Hall, G. Karady, and J. Renowden. Nonceramic insulators for transmission lines. IEEE Transactions on power Delivery, Vol. 4, No. 4, 1989, pp. 2214-2221.

[7] Hackam, R. Outdoor HV composite polymeric insulators. IEEE Transactions on Dielectrics and Electrical Insulation, Vol. 6, No. 5, 1999, pp. 557-585.

[8] Cherney, E. A., and R. S. Gorur. RTV silicone rubber coatings for outdoor insulators. IEEE Transactions on Dielectrics and Electrical Insulation, Vol. 6, No.5, 1999, pp. 605-611.

[9] Amin, M., M. Akbar, and M. N. Khan. Aging investigations of polymeric insulators: Overview and bibliography. IEEE Electrical Insulation Magazine, Vol. 23, No. 4, 2007, pp. 44-50.

[10] Amin, M., and M. Salman. Aging of polymeric insulators (an overview). Reviewv on Advance Materials Science, Vol. 13, No. 2, 2006, pp. 93-116.

[11] Agarwal, V. K., Aging of multistressed polymeric insulators. IEEE transactions on electrical insulation, Vol. 24, No. 5, 1989, pp. 741-764.

[12] Gorur, R. S. Status assessment of composite insulators for outdoor HV applications. In Proceedings of 5th IEEE International Conference on Properties and Applications of Dielectric Materials, May 25-30, 1997, Seoul, Korea, Vol. 1, pp. 35-38.

[13] Amin, M., M. Akbar, and M. Salman. Composite insulators and their aging: An overview. Science in China Series E: Technological Sciences, Vol. 50, No. 6, 2007, pp. 697-713.

[14] Chang, J. W., and R. S. Gorur. Surface recovery of silicone rubber used for HV outdoor insulation. IEEE Transactions on Dielectrics 
and Electrical Insulation, Vol. 1, No. 6, 1994, pp. 1039-1046.

[15] Gorur, R. S., E. A. Cherney, R. Hackam, and T. Orbeck. The electrical performance of polymeric insulating materials under accelerated aging in a fog chamber. IEEE Transactions on Power Delivery, Vol. 3, No. 3, 1988, pp. 1157-1164.

[16] Meyer, L. H., E. A. Cherney, and S. H. Jayaram. The role of inorganic fillers in silicone rubber for outdoor insulation alumina tri-hydrate or silica. IEEE Electrical Insulation Magazine, Vol. 20, No. 4, 2004, pp. 13-21.

[17] Fazelian, M., C. Y. Wu, T. C. Cheng, H. I. Nour, and L. J. Wang. A study on the profile of HVDC insulators-DC flashover performance. IEEE transactions on electrical insulation, Vol. 24, No. 1, 1989, pp. 119-125.

[18] Gorus, R. S., E. A. Cherney, and R. Hackam. The AC and DC performance of polymeric insulating materials under accelerated aging in a fog chamber. IEEE Transactions on Power Delivery, Vol. 3, No. 4, 1988, pp. 1892-1902.

[19] Cheng, T. C., C. T. Wu, and A. Rodriquez-Penz. Contamination flashover of HVDC insulators. Final report. No. EPRI-EL-2016. Dept. of Electrical Engineering, University of Southern California, LoS Angeles, USA, 1981.

[20] Sorquist, T., and A. E. Vlastos. Outdoor polymeric insulators longterm exposed to HVDC. In Proceedings of 1996 IEEE Transmission and Distribution Conference and Exposition, September 15-20, 1996, Los Angeles, California, USA, pp. 135-142.

[21] Guide, S. T. R. I. Hydrophobicity classification guide. Guide 1, No. 92/1, 1992.

[22] Ahmadi-Joneidi, I., A. A. Shayegani-Akmal, and H. Mohseni. Lifetime prediction of $20 \mathrm{kV}$ field-aged silicone rubber insulators via condition assessment. IEEE Transactions on Dielectrics and Electrical Insulation, Vol. 24, No. 6, 2017, pp. 3612-3621.

[23] International Electrotechnical Commission. Artificial pollution tests on high voltage insulators to be used on AC systems. IEC Publication 60507, Ed. 1, 1991.

[24] International Electrotechnical Commission. Selection and dimensioning of high voltage for polluted conditions part 1: definitions information and general principles. IEC 60815-1, Ed. 1, Geneva, Switzerland, International Organization for Standardization, 2002.

[25] Lee, C. J. Field experience and pollution monitoring of composite long rod insulators. IET, 1995, pp. 204-209.

[26] Mavrikakis, N., K. Siderakis, P. N. Mikropoulos, and N. Katsarakis. Condition assessment of a field-aged $150 \mathrm{kV}$ HTV SIR suspension insulator following flashover. In ISH 19th International Symposium on High Voltage Engineering, Pilsen, Czech Republic, August 23-28, 2015.

[27] Gustavsson, T. G., S. M. Gubanski, H. Hillborg, Sigbritt Karlsson, and U. W. Gedde. Aging of silicone rubber under ac or dc voltages in a coastal environment. IEEE Transactions on Dielectrics and Electrical Insulation, Vol. 8, No. 6, 2001, pp. 1029-1039.

[28] Hillborg, H., and U. W. Gedde. Hydrophobicity changes in silicone rubbers. IEEE Transactions on Dielectrics and Electrical insulation, Vol. 6, No. 5, 1999, pp. 703-717.

[29] Vlastos, A. E., and E. Sherif. Natural ageing of EPDM composite insulators. IEEE transactions on power delivery, Vol. 5, No. 1, 1990, pp. 406-414.

[30] Kumara, S., S. Alam, I. R. Hoque, Y. V. Serdyuk, and S. M. Gubanski. DC flashover characteristics of a polymeric insulator in presence of surface charges. IEEE Transactions on Dielectrics and Electrical Insulation, Vol. 19, No. 3, 2012, pp. 1084-1090.
[31] Das-Gupta, D. K. Surface charge decay on insulating films. In Proceedings Second International Conference on Properties and Applications of Dielectric Materials, September 12-16, 1988, Beijing, China, pp. 602-605.

[32] Llovera, P., and P. Molinié. New methodology for surface potential decay measurements: application to study charge injection dynamics on polypropylene films. IEEE transactions on dielectrics and electrical insulation, Vol. 11, No. 6, 2004, pp. 1049-1056.

[33] Gao, Y., J. Wang, F. Liu, and B. Du. Surface potential decay of negative corona charged epoxy/Al 203 nanocomposites degraded by 7.5-MeV electron beam. IEEE Transactions on Plasma Science, Vol. 46, No. 7, 2018, pp. 2721-2729.

[34] Gubanski, S. M., Modern outdoor insulation-concerns and challenges. IEEE Electrical Insulation Magazine, Vol. 21, No. 6, 2005, pp. 5-11.

[35] Cherney, E. A., A. El-Hag, S. Li, R. S. Gorur, L. Meyer, I. Ramirez, et al. RTV silicone rubber pre-coated ceramic insulators for transmission lines. IEEE Transactions on Dielectrics and Electrical Insulation, Vol. 20, No. 1, 2013, pp. 237-244.

[36] Chang, J., and R. S. Gorur. Surface hydrophobicity of polymeric materials used for outdoor insulation applications. In 6th Int. Symp. on High Voltage Eng., New Orleans, Louisiana, US, August 28-September 1, 1989.

[37] Kim, J., M. K. Chaudhury, and M. J. Owen. Hydrophobicity loss and recovery of silicone HV insulation. IEEE Transactions on Dielectrics and Electrical Insulation, Vol. 6, No. 5, 1999, pp. 695702.

[38] Marzinotto, M., E. A. Cherney, and G. Mazzanti. RTV pre-coated cap-and-pin toughened glass insulators-a wide experience in the Italian overhead transmission system. In 2015 IEEE Conference on Electrical Insulation and Dielectric Phenomena (CEIDP), Ann Arbor, Michigan, USA, October 18-21, 2015, pp. 150-153.

[39] Gorur, R. In praise of coated insulators. INMR Q4, No. 20, 2011, pp.12-13.

[40] Guan, Z. C., and J. Q. Xue. Techn.Rep. HV Lab, Tsinghua University, Beijing, China, May, 1991.

[41] Cherney, E. A. Silicone rubber dielectrics modified by inorganic fillers for outdoor high voltage insulation applications. IEEE Transactions on Dielectrics and Electrical Insulation, Vol. 12, No. 6, 2005, pp. 1108-1115.

[42] Kim, S. H., Electrical performance and surface analysis of RTV silicone rubber coatings for HV outdoor insulators. Doctoral Dissertation. University of Windsor, Canada, 1992.

[43] Marzinotto, M., G. Lavecchia, M. R. Guarniere, A. Posati, M. Rebolini, J. M. George, et al. DC-toughened glass insulators precoated with RTV silicone rubber-Field returns from aged samples installed on HVDC lines. In 2013 IEEE International Conference on Solid Dielectrics (ICSD), June 30-July 4, 2013, Bologna, Italy, pp. 170-173.

[44] IEC, TS. 60815-1., Selection and dimensioning of high voltage insulators intended for use in polluted conditions - Part 1: Definitions, information and general principles, Ed. 1, 2008.

[45] Flemming, H. C. Relevance of biofilms for the biodeterioration of surfaces of polymeric materials. Polymer degradation and stability, Vol. 59, No. 1-3, 1998, pp. 309-315.

[46] Wallström, S., and S. Karlsson. Biofilms on silicone rubber insulators; microbial composition and diagnostics of removal by use of ESEM/EDS: Composition of biofilms infecting silicone rubber insulators. Polymer degradation and stability, Vol. 85, No. 2, 2004, pp. 841-846. 
[47] Kumagai, S. Influence of algal fouling on hydrophobicity and leakage current on silicone rubber. IEEE Transactions on Dielectrics and Electrical Insulation, Vol. 14, No. 5, 2007, pp.1201-1206.

[48] Gorur, R. S., J. Montesinos, R. Roberson, J. Burnham, and R. Hill. Mold growth on nonceramic insulators and its impact on electrical performance. IEEE Transactions on Power Delivery, Vol. 18, No. 2, 2003, pp. 559-563.

[49] Dinesh, M. N., N. Vasudev, P. V. Nambudri, K. Suryanarayana, K. N. Ravi, and V. Krishnan. Performance of composite insulators with and without bio contamination. In 2008 International Conference on High Voltage Engineering and Application, November 9-13, 2008, Chongqing, China, pp. 124-127.

[50] Coowar, F., and P. R. P. Hoole. Discharge characteristics of algacontaminated string insulators in the tropics. Electric power systems research, Vol. 15, No. 3, 1988, pp. 215-218.

[51] Gorur, R. S., J. Montesinos, R. Roberson, J. Burnham, and R. Hill. Mold growth on nonceramic insulators and its impact on electrical performance. In 1999 IEEE Transmission and Distribution Conference (Cat. No. 99CH36333), April 11-16, 1999, New Orleans, Los Angeles, USA, Vol. 2, pp. 818-822.

[52] Yang, S., Z. Jia, X. Ouyang, H. Bai, and R. Liu. Hydrophobicity characteristics of algae-fouled HVDC insulators in subtropical climates. Electric Power Systems Research, Vol. 163, 2018, pp.626637.

[53] Ouyang, X., Z. Jia, S. Yang, X. Shang, X. Wang, H. Chen, D. Zhou, et al. Influence of algae growth on the external insulation performance of HVDC insulators. IEEE Transactions on Dielectrics and Electrical Insulation, Vol. 25, No. 1, 2018, pp. 263-271.

[54] Schneider, H. M., W. W. Guidi, J. T. Burnham, R. S. Gorur, and J. F. Hall. Accelerated aging and flashover tests on $138 \mathrm{kV}$ nonceramic line post insulators. IEEE transactions on power delivery, Vol. 8, No. 1, 1993, pp. 325-336.

[55] Garcia, R. W. S., M. S. Torres, F. R. Silva, E. Gomes, S. A. Bade, J. A. Argolo, et al. Natural and accelerated aging of composite insulators. In Conference Record of the 1998 IEEE International Symposium on Electrical Insulation (Cat. No. 98CH36239), June 7-10, 1998, Arlington, Virginia, USA, Vol. 2, pp. 329-333.

[56] Ito, H., T. Nakanishi, R. Matsuoka, N. Ohtaki, N. Okada, M. Ishiwari, et al. Characteristics of weathershed materials for polymer insulators by accelerated aging tests. In Proceedings of the 6th International Conference on Properties and Applications of Dielectric Materials (Cat. No. 00CH36347), June 21-26, 2000, Xi'an, China, Vol. 2, pp. 633-636.

[57] Cho, H. G., S. W. Han, and U. Y. Lee. Multi-aging test technology for estimating long time performance of polymer insulators. In Conference Record of the 2002 IEEE International Symposium on Electrical Insulation (Cat. No. 02CH37316), April 7-10, 2002, Boston, Massachusetts, USA, pp. 232-236.

[58] Lee, J. B., I. K. Song, J. Y. Kim, B. S. Lee, and T. H. Kwon. Aging characteristics of polymer lightning arrester by multi-stress accelerated aging test. In Proceedings of the 2004 IEEE International Conference on Solid Dielectrics (ICSD), July 5-9, 2004. Toulouse, France, Vol. 1, pp. 371-374.

[59] Sundararajan, R., C. Olave, E. Romero, and B. Trepanier. Modified IEC 5000-h multistress aging of 28-kV thermoplastic elastomeric insulators. IEEE transactions on power delivery, Vol. 22, No. 2, 2007, pp. 1079-1085.

[60] Gutman, I., M. Gullo, M. Gårdestedt, S. Bucan, J. F. Goffinet, J. Seifert, et al. Long-term performance of composite station insulators with larger diameters: laboratory tracking and erosion test vs. service experience. In CIGRE Session, 2016.

[61] International Electrotechnical Commission, HV Polymeric Insulators for Indoor and Outdoor Use Tracking and Erosion Testing by Wheel Test and 5000h Test. IEC 62730, 2012.

[62] International Electrotechnical Commission, Polymeric insulators for outdoor and outdoor use with anominal voltage greater than $1000 \mathrm{~V}$ - General definitions, test procedures and acceptance criteria, IEC 62217, 2012.

[63] Verma, A. R., G. S. Reddy, and R. Chakraborty. Multistress aging studies on polymeric insulators. IEEE Transactions on Dielectrics and Electrical Insulation, Vol. 25, No. 2, 2018, pp. 524-532.

[64] Ehsani, M., H. Borsi, E. Gockenbach, J. Morshedian, G. R. Bakhshandeh, and A. A. Shayegani. Effect of aging on dielectric behavior of outdoor polymeric insulators. In Proceedings of the 2004 IEEE International Conference on Solid Dielectrics (ICSD), July 5-9, 2004, Toulouse, France, Vol. 1, pp. 312-315.

[65] Gorur, R. S., D. W. Gedach, and R. S. Thallam. Aging in outdoor insulating polymers due to UV and high temperature. In 1991 Annual Report. Conference on Electrical Insulation and Dielectric Phenomena, October 20-23, 1991, Knoxville, Tennessee, USA, pp. 268-273.

[66] Gorur, R. S., G. G. Karady, A. Jagota, M. Shah, and A. M. Yates. Aging in silicone rubber used for outdoor insulation. IEEE Transactions on Power Delivery, Vol. 7, No. 2, 1992, pp. 525-538.

[67] Gorur, R. S., L. A. Johnson, and H. C. Hervig. Contamination performance of silicone rubber cable terminations. IEEE transactions on power delivery, Vol. 6, No. 4, 1991, pp. 1366-1373.

[68] Fourmigue, J. M., M. Noel, and G. Riquel. Aging of polymeric housing for HV insulators: comparison between natural and artificial testing. In Proceedings of 1995 Conference on Electrical Insulation and Dielectric Phenomena, October 22-25, 1995, Virginia, USA, pp. 404-407.

[69] Chakraborty, R., Performance of silicone rubber insulators under thermal and electrical stress. IEEE Transactions on Industry Applications, Vol. 53, No. 3, 2017, pp. 2446-2454.

[70] Venkatesulu, B., and M. J. Thomas. Long-term accelerated weathering of outdoor silicone rubber insulators. IEEE Transactions on Dielectrics and Electrical Insulation, Vol. 18, No. 2, 2011, pp. 418-424.

[71] Olave, C., E. Romero, P. Trinidad, R. Sundararajan, and B. Trepanier. 5000h multistress aging of $28 \mathrm{kV}$ TPE insulators. In IEEE Power Engineering Society General Meeting, June 16, 2005, pp. 1006-1012.

[72] Sundararajan, R., E. Soundarajan, A. Mohammed, and J. Graves. Multistress accelerated aging of polymer housed surge arresters under simulated coastal Florida conditions. IEEE transactions on Dielectrics and Electrical Insulation, Vol. 13, No. 1, 2006, pp. 211-226.

[73] Xu, G., P. B. McGrath, and C. W. Burns. Accelerated environmental and electrical aging of polymer insulators. In Proceedings of Conference on Electrical Insulation and Dielectric PhenomenaCEIDP'96, October 23, 1996, Millbrae, California, USA, Vol. 1, pp. 404-407.

[74] Nekeb, A. S., N. Harid, and A. Haddad. Effect of uv irradiation on the leakage current of polymeric insulators. In 2011 46th International Universities' Power Engineering Conference (UPEC), September 5, 2011, Soest, Germany, pp. 1-4.

[75] Verma, A. R., and B. S. Reddy. Aging studies on polymeric insulators under DC stress with controlled climatic conditions. Polymer Testing, Vol. 68, 2018, pp. 185-192. 
[76] International Electrotechnical Commission IEC, Genf., Guidance on the measurement of wettability of insulator surfaces. IEC 62073-2003, 2003.

[77] Li, S., X. Liang, Y. Gao, Y. Liu, Y. Yin, and Z. Li. A modified $5000 \mathrm{~h}$ test procedure for silicone rubber insulator based on contamination and hydrophobicity change simulation. IEEE Transactions on Dielectrics and Electrical Insulation, Vol. 24, No. 3, 2017, pp. 1818-1828.

[78] Swift, D. A., C. Spellman, and A. Haddad. Hydrophobicity transfer from silicone rubber to adhering pollutants and its effect on insulator performance. IEEE Transactions on Dielectrics and Electrical Insulation, Vol. 13, No. 4, 2006, pp. 820-829.

[79] Kim, J., M. K. Chaudhury, and M. J. Owen. Hydrophobicity loss and recovery of silicone HV insulation. IEEE Transactions on Dielectrics and Electrical Insulation, Vol. 6, No. 5, 1999, pp. 695 702.

[80] Gorur, R. S., E. A. Cherney, R. Hackam, and T. Orbeck. The electrical performance of polymeric insulating materials under accelerated aging in a fog chamber. IEEE Transactions on Power Delivery, Vol. 3, No. 3, 1988, pp. 1157-1164.

[81] Kumagai, S., X. Wang, and N. Yoshimura. Solid residue formation of RTV silicone rubber due to dry-band arcing and thermal decomposition. IEEE transactions on dielectrics and electrical insulation, Vol. 5, No. 2, 1998, pp. 281-289.

[82] Schneider, H. M., J. F. Hall, G. Karady, and J. Renowden. Nonceramic insulators for transmission lines. IEEE Transactions on Power Delivery, Vol. 4, No. 4, 1989, pp. 2214-2221.

[83] Kumagai, S., and N. Yoshimura. Tracking and erosion of HTV silicone rubber and suppression mechanism of ATH. IEEE Transactions on dielectrics and electrical insulation, Vol. 8, No. 2, 2001, pp. 203-211.

[84] Yoshimura, N., S. Kumagai, and B. Du. Research in Japan on the tracking phenomenon of electrical insulating materials. IEEE Electrical Insulation Magazine, Vol. 13, No. 5, 1997, pp. 8-19.

[85] Kim, S. H., E. A. Cherney, R. Hackam, and K. G. Rutherford. Chemical changes at the surface of RTV silicone rubber coatings on insulators during dry-band arcing. IEEE Transactions on Dielectrics and Electrical Insulation, Vol. 1, No. 1, 1994, pp. 106-123.

[86] Homma, H., C. L. Mirley, J. Ronzello, and S. A. Boggs. Field and laboratory aging of RTV silicone insulator coatings. IEEE Transactions on power delivery, Vol. 15, No. 4, 2000, pp. 1298-1303.

[87] Konig, D., I. Quint, P. Rosch, and B. Bayer. Surface discharges on contaminated epoxy insulators. IEEE transactions on electrical insulation, Vol. 24, No. 2, 1989, pp. 229-237.

[88] Yoshimura, N., S. Kumagai, and B. Du. Research in Japan on the tracking phenomenon of electrical insulating materials. IEEE Electrical Insulation Magazine, Vol. 13, No. 5, 1997, pp. 8-19.

[89] Heger, G., H. J. Vermeulen, J. P. Holtzhausen, and W. L. Vosloo. A comparative study of insulator materials exposed to high voltage $A C$ and DC surface discharges. IEEE Transactions on Dielectrics and Electrical Insulation, Vol. 17, No. 2, 2010, pp. 513-520.

[90] Moreno, V. M., and R. S. Gorur. AC and DC performance of polymeric housing materials for HV outdoor insulators. IEEE transactions on dielectrics and electrical insulation, Vol. 6, No. 3, 1999, pp. 342-350.

[91] Chandrasekar, S., R. Sarathi, and M. G. Danikas. Analysis of surface degradation of silicone rubber insulation due to tracking under different voltage profiles. Electrical Engineering, Vol. 89, No. 6, 2007, pp. 489-501.
[92] Piah, M. A. M., A. Darus, and A. Hassan. Electrical tracking performance of LLDPE-natural rubber blends by employing combination of leakage current level and rate of carbon track propagation. IEEE Transactions on Dielectrics and Electrical Insulation, Vol. 12, No. 6, 2005, pp. 1259-1265.

[93] Mackevich, J., and S. Simmons. Polymer outdoor insulating materials. II. Material considerations. IEEE Electrical Insulation Magazine, Vol. 13, No. 4, 1997, pp. 10-16.

[94] Simmons, S., M. Shah, J. Mackevich, and R. J. Chang. Polymer outdoor insulating materials. Part III-Silicone elastomer considerations. IEEE Electrical Insulation Magazine, Vol. 13, No. 5, 1997, pp. 25-32.

[95] Wendt, E., and H. Jahn. Influence of Chemical Design of Insulating Silicone Compounds on Hydrophobic and Electrical Behaviour. In Insulator News and Market Rep. Conf. Proc., 2000.

[96] Kim, S. H., E. A. Cherney, and R. Hackam. The loss and recovery of hydrophobicity of RTV silicone rubber insulator coatings. IEEE Transactions on Power Delivery, Vol. 5, No. 3, 1990, pp. 1491 . 1500.

[97] Kloes, H. J., and D. Koenig. Multifactor-surface-tests of organic insulating materials in the early stage of degradation. In Conference Record of the 1996 IEEE International Symposium on Electrical Insulation, June 16-19, 1996, Montreal, Quebec, Canada, Vol. 1, pp. 296-299.

[98] Chang, R. J., and L. Mazeika. Analysis of electrical activity associated with inclined-plane tracking and erosion of insulating materials. IEEE Transactions on Dielectrics and Electrical Insulation, Vol. 7, No. 3, 2000, pp. 394-400.

[99] Kim, S. H., E. A. Cherney, and R. Hackam. Effects of filler level in RTV silicone rubber coatings used in HV insulators. IEEE Transactions on electrical insulation, Vol. 27, No. 6, 1992, pp. 1065-1072.

[100] Landel, R. F., and L. E. Nielsen. Mechanical properties of polymers and composites, CRC press, December 14, 1993.

[101] Rowland, S. M., G. P. Bruce, Y. Liu, A. Krivda, and L. E. Schmidt. Use of image analysis in DC inclined plane tracking tests of nano and micro composites. IEEE Transactions on Dielectrics and Electrical Insulation, Vol. 18, No. 2, 2011, pp. 365-374.

[102] Du, B. X., J. W. Zhang, and Y. Liu. Effect of concentration on tracking failure of epoxy/TiO2 nanocomposites under dc voltage. IEEE Transactions on Dielectrics and Electrical Insulation, Vol. 19, No. 5, 2012, pp. 1750-1759.

[103] Du, B. X., J. W. Zhang, and Y. Gao. Effects of TiO2 particles on surface charge of epoxy nanocomposites. IEEE Transactions on Dielectrics and Electrical Insulation, Vol. 19, No. 3, 2012, pp. 755762.

[104] Cherney, E. A. Silicone rubber dielectrics modified by inorganic fillers for outdoor high voltage insulation applications. IEEE Transactions on Dielectrics and Electrical Insulation, Vol. 12, No. 6, 2005, pp. 1108-1115.

[105] Gorur, R. S., E. A. Cherney, and R. Hackam. A Comparative of Polymer Insulating Materials Under Salt-Fog Conditions. IEEE El-21, 1986.

[106] Meyer, L. H., E. A. Cherney, and S. H. Jayaram. The role of inorganic fillers in silicone rubber for outdoor insulation alumina tri-hydrate or silica. IEEE Electrical Insulation Magazine, Vol. 20, No. 4, 2004, pp. 13-21.

[107] Ghunem, R. A., S. H. Jayaram, and E. A. Cherney. Investigation into the eroding dry-band arcing of filled silicone rubber under DC using wavelet-based multiresolution analysis. IEEE Transactions on Dielectrics and Electrical Insulation, Vol. 21, No. 2, 2014, pp. 
713-720.

[108] Kumagai, S., and N. Yoshimura. Tracking and erosion of HTV silicone rubber and suppression mechanism of ATH. IEEE Transactions on dielectrics and electrical insulation, Vol. 8, No. 2, 2001. pp. 203-211.

[109] ASTM D2303-97, Standard Test Methods for LiquidContaminant, Inclined Plane Tracking and Erosion of Insulating Materials, 1997.

[110] International Electrotechnical Commission, Electrical Insulating Materials Used Under Severe Ambient Conditions-Test Methods for Evaluating Resistance to Tracking and Erosion, IEC. 60587, 2007.

[111] Du, B. X., and H. Xu. Effects of thermal conductivity on dc resistance to erosion of silicone rubber/BN nanocomposites. IEEE Transactions on Dielectrics and Electrical Insulation, Vol. 21, No. 2, 2014, pp. 511-518.

[112] Krivda, A., L. E. Schmidt, X. Kornmann, H. Ghorbani, A. Ghorbandaeipour, M. Eriksson, et al. Inclined-plane tracking and erosion test according to the IEC 60587 standard. IEEE Electrical Insulation Magazine, Vol. 25, No. 6, 2009, pp. 14-22.

[113] Moreno, V. M., and R. S. Gorur. AC and DC performance of polymeric housing materials for HV outdoor insulators. IEEE transactions on dielectrics and electrical insulation, Vol. 6, No. 3, 1999, pp. 342-350.

[114] Chandrasekar, S., R. Sarathi, and M. G. Danikas. Analysis of surface degradation of silicone rubber insulation due to tracking under different voltage profiles. Electrical Engineering, Vol. 89, No. 6, 2007, pp. 489-501.

[115] Bruce, G. P., S. M. Rowland, and A. Krivda. DC inclined-plane testing of silicone rubber formulations. In 2008 Annual Report Conference on Electrical Insulation and Dielectric Phenomena, October 26-29, 2008, Quebec, Canada, pp. 196-199.

[116] Vas, J. V., B. Venkatesulu, and M. J. Thomas. Tracking and erosion of silicone rubber nanocomposites under DC voltages of both polarities. IEEE Transactions on Dielectrics and Electrical Insulation, Vol. 19, No. 1, 2012, pp. 91-98.
[117] Ghunem, R. A., S. H. Jayaram, and E. A. Cherney. Comparative inclined plane tests on silicone and EPDM elastomers under DC. In 2013 IEEE Electrical Insulation Conference (EIC), June 2-5, 2013, Ottawa, Ontario, Canada, pp. 356-359.

[118] Ghunem, R. A., S. H. Jayaram, and E. A. Cherney. Suppression of silicone rubber erosion by alumina trihydrate and silica fillers from dry-band arcing under DC. IEEE Transactions on Dielectrics and Electrical Insulation, Vol. 22, No. 1, 2015, pp. 14-20.

[119] Tomer, V., G. Polizos, E. Manias, and C. A. Randall. Epoxy-based nanocomposites for electrical energy storage. I: Effects of montmorillonite and barium titanate nanofillers. Journal of Applied Physics, Vol. 108, No. 7, 2010, id. 074116.

[120] Alapati, S., and M. J. Thomas. Electrical treeing and the associated PD characteristics in LDPE nanocomposites. IEEE Transactions on Dielectrics and Electrical Insulation, Vol. 19, No. 2, 2012, pp. 697-704.

[121] Li, Z., K. Okamoto, Y. Ohki, and T. Tanaka. Effects of nano-filler addition on partial discharge resistance and dielectric breakdown strength of Micro-Al203 Epoxy composite. IEEE Transactions on Dielectrics and Electrical Insulation, Vol. 17, No. 3, 2010, pp. 653-661.

[122] Sarathi, R., P. R. Kumar, and R. K. Sahu. Analysis of surface degradation of epoxy nanocomposite due to tracking under $A C$ and DC voltages. Polymer degradation and stability, Vol. 92, No. 4, 2007, pp. 560-568.

[123] Du, B. X., and Y. G. Guo. Tracking resistance of epoxy/Al 20 3 nanocomposites under DC voltage. IEEE Transactions on Dielectrics and Electrical Insulation, Vol. 22, No. 1, 2015, pp. 109. 116.

[124] Xing, Z., C. Zhang, X. Hu, P. Guo, J. Zhang, Z. Wang, et al. Surface tracking of $\mathrm{MgO} /$ epoxy nanocomposites: Effect of surface hydrophobicity. Applied Sciences, Vol. 9, No. 3, 2019, id. 413. 